\title{
POLÍTICA CURRICULAR E NEOLIBERALISMO: UMA CRÍTICA À BASE NACIONAL COMUM CURRICULAR A PARTIR DO LEGADO FREIRIANO
}

\author{
LUCILENE AMARANTE \\ ANDRESSA GARCIA DE MACEDO \\ JANI AlVES DA SILVA MOREIRA \\ Universidade Estadual de Maringá (UEM), Maringá, Paraná, Brasil
}

\begin{abstract}
Resumo: Neste artigo, analisa-se o ideário político-econômico do neoliberalismo presente na política curricular da educação básica e no contexto de aprovação da BNCC, além de estabelecer uma relação de contraposição com o legado freiriano, especialmente com sua concepção de escola problematizadora, justa e democrática. Apresentam-se as proposições metodológicas a partir da análise e compreensão sobre a conjuntura histórica, política e econômica vigente. O texto é composto pelos resultados de uma pesquisa exploratória, de caráter bibliográfico, a respeito dos principais postulados do neoliberalismo, doutrina econômica que acaba por justificar os princípios da desigualdade e da exclusão social. Tais resultados são analisados à luz da proposta de um currículo problematizador, composto por conhecimentos apropriados a uma concepção de escola despojada da lógica do mercado. Considera-se, enfim, que Paulo Freire propõe um currículo construído a partir da realidade dos estudantes, que seja capaz de diminuir, pelo conhecimento, as desigualdades resultantes da adoção do neoliberalismo.
\end{abstract}

Palavras-chave: Política Curricular. Paulo Freire. Neoliberalismo. Emancipação. BNCC.

\section{INTRODUÇÃO}

O presente artigo traz à baila, a partir do contexto de intensificação do neoliberalismo e dos novos contornos que foram criados no cenário educacional, a análise sobre o ideário político-econômico que orienta a política curricular brasileira, especialmente a política curricular da educação básica, configurada após a aprovação da BNCC (BRASIL, 2017). A finalidade é estabelecer relações analíticas com o legado freiriano, que concebe uma escola justa e democrática, e contrapor-se ao ideário neoliberal reproduzido no que se ensina na escola pública.

A educação é determinada por um tempo histórico e por uma sociedade em constante transformação, na qual os homens que nela atuam também se transformam. Com essa premissa, por meio de uma análise crítica e contextualizada, discutimos o ideário político-econômico do neoliberalismo e sua influência nos currículos escolares, contrapondo-o ao legado histórico e pedagógico freiriano para uma escola problematizadora, justa e democrática. 
As alterações que vêm ocorrendo nas políticas curriculares brasileiras e no paradigma dominante, as quais, para atender ao âmbito político e econômico, impõem novos objetivos para a educação, justificam a análise do pensamento educacional de Paulo Freire.

O propósito da pesquisa, cujos resultados são expostos neste artigo, foi apreender os preceitos neoliberais na reforma educacional brasileira, além de estabelecer um diálogo com os pressupostos freirianos, especialmente porque as reformas educacionais no âmbito do currículo, tanto no campo internacional como no nacional, são marcadas por enfrentamentos, contradições e interesses antagônicos.

Para dar conta da abrangência da temática, a análise prioriza a contextualização do cenário educacional atual, bem como político-econômico, que propicia mudanças no mundo do trabalho e, consequentemente, nas diretrizes políticas curriculares brasileira. Portanto, a metodologia utilizada na pesquisa estabelece uma mediação analítica crítica com os dados fornecidos pelas fontes primárias, mediante a compreensão articulada entre as diretrizes políticas curriculares atuais e o legado Freiriano.

Ao discutir Paulo Freire, propomos a reflexão sobre uma nova vertente para o currículo, isto é, um currículo dialógico e problematizador que, expressando a realidade dos estudantes e organizado com base em conhecimentos sistematizados e fundamentais para a transformação social, seja capaz de promover a criticidade e a emancipação humana. Durante a pesquisa, por meio de análise bibliográfica e exploratória, construiu-se um diagnóstico crítico e contextualizado com a intenção de responder: quais as possibilidades de uma organização curricular que promova uma efetiva educação emancipatória latino-americana?

Em um primeiro momento, abordamos a concepção histórica do neoliberalismo e sua influência na organização da sociedade, já que as concepções e os princípios da lógica mercadológica estão presentes de forma intensa no cenário educacional e nas políticas educacionais para a educação na América Latina e no Caribe. Em um segundo momento, analisamos as diretrizes e as concepções neoliberais presentes nas políticas curriculares da educação básica brasileira, considerando que o currículo norteia o trabalho de formação dos estudantes. Por último, apresentamos algumas proposições para que, por meio do legado histórico e pedagógico de Paulo Freire, evidenciado nas obras Pedagogia do Oprimido (2005) e Pedagogia da esperança - um reencontro com a pedagogia do oprimido (2015), se possa pensar um currículo que se oponha ao ideário político-econômico do neoliberalismo.

\section{NEOLIBERALISMO E SUA INTENSIFICAÇÃO NO CONTEXTO EDUCACIONAL ATUAL}

Ao longo da história, especialmente desde a promulgação da Constituição da República Federativa do Brasil 1988, ocorre um esforço do Estado em promover políticas para o currículo, principalmente para a Educação Básica, com o intuito de adequar o que se ensina na escola às demandas emergenciais de nossa sociedade a qual é movida por interesses do mercado. As políticas curriculares para a educação básica que, 
LUCILENE, A.; MACEDO, A. G. de i MOREIRA, J. A. da S.

historicamente se efetivaram no Brasil, foram determinadas pelas relações que se delinearam na base produtiva da sociedade e na educação, correspondendo às necessidades de diferentes ordens. Nesse item, nosso propósito é analisar a intensificação neoliberal no atual contexto.

Os conceitos básicos do neoliberalismo, à luz de seus proponentes clássicos, caracterizam uma nova leitura do liberalismo para as condições do capitalismo no século XX. O liberalismo, por sua vez, é uma doutrina política formulada no século XVIII, tendo como principal teórico Adam Smith, em seu clássico $A$ riqueza das nações (1996), cuja primeira versão foi publicada em 1776. Podemos inferir que o projeto neoliberal foi impulsionado, a partir da década de 1970, na América Latina e no Caribe, essencialmente pela política internacional adotada pelo Banco Mundial, assim como o Fundo Monetário Internacional, o que propiciou um Estado gerenciado pelas leis do mercado, em vez de um Estado fornecedor do desenvolvimento econômico e social, de maneira que as possibilidades de interferência internacional na elaboração de políticas educacionais expandiram.

A concepção de educação para o neoliberalismo deve seguir a lógica do mercado, adaptando-se aos pressupostos de qualidade mediante a concorrência, eficiência e eficácia medidos por resultados. Nesse sentido, a centralidade das competências na Base Nacional Comum Curricular (BRASIL, 2017) é um aspecto importante a ser analisado sobre a perspectiva neoliberal nas políticas curriculares, visto que o enfoque nas competências, explicitados na Base Nacional Comum Curricular (BRASIL, 2017), encontram-se relacionadas à qualificação exigida pelo mercado no contexto de acumulação do capital. Na seção dos fundamentos pedagógicos, a Base (BRASIL, 2017, p. 13) justifica a adoção da concepção de competências em virtude do "enfoque adotado nas avaliações internacionais da OCDE".

Vale salientar que, a partir da crise de 2008, configurações se acirraram no mundo do trabalho, com a Indústria 4.0, na fase da financeirização do capital, na qual novas reorganizações e formas de adaptações foram postas em um modo de produção cada vez mais destituído do trabalhador enquanto força de trabalho, mas com "um forte processo de proletarização e de explosão desse novo proletariado de serviços que se expande em escala global", portanto, há uma nova morfologia do trabalho e das suas formas de organização. É nesse contexto de intensas reconfigurações que surge o denominado "novo neoliberalismo" (PUELLO-SOCARRÁS, 2008 e 2021). Como analisa o autor, existem três elementos analíticos estruturais a serem levados em conta para compreender as novas configurações desta teoria política-econômica, sendo:

i) o tipo de Estado: Punitivo, Empreendedor e de Trabalho, EPET; ii) os modos de Governo e Organizacional (governança e pós-nova gestão público-privada); e, iii) a modalidade de ação institucional (regulatória). Em conjunto, estas dimensões configuram a atual armação neoliberal. Tanto a renovação heterodoxa do neoliberalismo quanto o chamado: "Consenso da Regulação" (estatal dos mercados) são chaves insubstituíveis para dar conta das novas características do capitalismo no século XXI (PUELLOSOCARRÁS, 2011, p. 40). 
Algumas considerações teórico-metodológicas são primordiais para esclarecer a influência do neoliberalismo no âmbito das políticas curriculares. Hegemonia, por exemplo, é uma categoria que nos auxilia a analisar as relações de classes que permeiam a sociedade e a política curricular brasileira, tornando-se um meio para a análise das estratégias políticas (CURY, 1987). O autor define hegemonia como "a capacidade de direção cultural e ideológica que é apropriada por uma classe, exercida sobre o conjunto da sociedade civil, articulando seus interesses particulares com os das demais, de modo que eles venham a se constituir em interesse geral" (CURY, 1987, p. 48).

Destacamos que as reformas educacionais implementadas em diferentes tempos são resultado do pensamento dos homens em sociedade, homens esses condicionados pelas forças produtivas. Para Viana (2008, p. 4), "o modo de produção capitalista é a fonte explicativa para as transformações estatais e ideológicas e não o contrário", ou seja, as origens do neoliberalismo encontram-se nas transformações do capitalismo, muito mais do que nas ideologias. Ball (2014, p. 42) corrobora esse entendimento e acrescenta sua ideia a respeito do papel regulador que o Estado exerce para a consolidação das estratégias econômicas neoliberais, uma vez que "o neoliberalismo também atua nas instituições do setor público e no Estado de fato, o Estado é importante para o neoliberalismo como regulador e criador de mercado".

Segundo Laval $(2019$, p. 9), o neoliberalismo é o grande responsável pela degradação mundial das condiç̃̃es de trabalho e de vida, bem como da "deterioração das instituições educacionais, universitárias e científicas". Diante disso, consideramos que as mutações no capitalismo, ao menos em parte, explicam a tendência das reformas educacionais em curso no Brasil: o neoliberalismo atual não objetiva transformar a escola rapidamente, mas sim construir uma escola em consonância com os pressupostos capitalistas.

A lógica neoliberal defende a privatização como um modelo para se alcançar sucesso. Em relação a isso, as reformas sucessivas promovidas nas políticas educacionais revelam um viés neoliberal na medida em que a educação passa a ser considerada um bem essencialmente privado (LAVAL, 2019), cujo valor é econômico. Pondera Souza (2003) que as reformas atuais apresentam postulados voltados para o individualismo liberal, pois possuem uma concepção de reforma relacionada com progresso, no qual é desconsiderada a relação entre a cultura e o cotidiano escolar.

Nesse sentido, entendemos que o panorama de reformas educacionais atuais seria mais de antirreformas, já que as políticas e os enunciados discursivos contemplam terminologias que se referem ao alcance de sucesso individual e à ascensão social via eficiência e eficácia, medidas pelos resultados e avaliações da competição, do mérito e do empreendedorismo. Conceitualmente, referem-se à formação de mão de obra para a inserção dos sujeitos em um contexto latino-americano neoliberal para se alcançar o chamado desenvolvimento sustentável da economia, lema amplamente divulgado pelos Organismos Internacionais do Sistema da Organização Unidas (ONU) e pelo mercado econômico. Tais conceitos podem ser constatados na agenda de desenvolvimento sustentável pós-2015 da Declaração de Incheon, na qual foram 
LUCILENE, A.; MACEDO, A. G. de; MOREIRA, J. A. da S.

estabelecidos os Objetivos de Desenvolvimento Sustentável para a educação (ODS4) até 2030 (Agenda E2030).

Nessa declaração, a educação é considerada o principal motor para o desenvolvimento. Afirma-se que as crianças, os jovens e os adultos devem desenvolver as competências de que necessitam para trabalhar e viver ao longo da vida e que a Agenda E2030 garantirá uma base sólida de conhecimentos e habilidades aos indivíduos (ORGANIZAÇÕES DAS NAÇÕES UNIDAS PARA A EDUCAÇÃO, A CIÊNCIA, E A CULTURA, 2016).

Tais conceitos, articulados aos princípios da teoria do capital humano1, são incutidos de forma inconsciente em cada um, gerando um processo de alienação e direcionando a educação cada vez mais para a reprodução dos interesses privados de lucro e competitividade. Conforme afirmam Alves, Moreira e Puziol (2009), o investimento em educação visa o desenvolvimento econômico e a produção de capacidade de trabalho, o que potencializa a responsabilização dos indivíduos pelo seu sucesso ou insucesso.

De acordo com Corrêa e Morgado (2018), a reforma curricular proposta pelo atual documento oficial orientador dos currículos brasileiros, intitulado de Base Nacional Comum Curricular (BRASIL, 2017, n.p), reflete "os interesses de empresas, fundações e instituições filantrópicas, geralmente financiadas pela alocação de impostos de grandes corporações".

Destaca-se sua consonância com as recomendações da Agenda E2030, na qual se focalizam as habilidades e as competências necessárias ao novo modelo de exploração promovido pela mundialização do capital. É o que mostram a Meta 4.4 da Agenda E2030, na qual se evidencia a importância de os jovens terem habilidades e competências para atender às demandas do setor produtivo. A Meta 4.1, por sua vez, ressalta a importância dos resultados de aprendizagem, os quais devem ser eficazes e relevantes. Assim, nas recomendações apresentadas na Agenda E2030 aos países do Caribe e da América Latina, fica evidente que formar as habilidades e as competências é um meio de preparar os jovens para atender às necessidades do capital.

Na concepção neoliberal, o homem é responsável por seu próprio sucesso e por suas escolhas, sendo levado a acreditar que todos são capazes de conquistar seus objetivos em uma sociedade ideologicamente marcada pelos interesses mercadológicos, competitivos e financeiros: "à afirmação da plena autonomia dos indivíduos sem amarras [...] correspondem instituições que parecem não ter outra razão de ser que não seja servir a interesses particulares" (LAVAL, 2019, p. 17). Essa concepção, como se pressupõe, está associada ao neoliberalismo e a uma transformação da economia capitalista, e este ideário mercadológico articula-se e reproduz-se às políticas curriculares.

Ao analisar os desdobramentos dessa lógica mercadológica no cenário educacional, vemos a ênfase no quesito qualidade da aprendizagem com base em resultados ou ranqueamentos de provas de avaliação externa, instrumento utilizado para monitorar e elevar a tal qualidade do sistema educacional, via preparação dos sujeitos para atuar no mundo do trabalho. 
A superação das desigualdades de classe, do domínio do capital e do mercado, que norteiam as relações sociais, somente será possível quando todos tiverem acesso aos conhecimentos historicamente produzidos. Uma sociedade somente se modifica pela apropriação crítica desses conhecimentos e pelo posicionamento que eles podem favorecer. A esse respeito, Saviani $(2013$, p. 13) expõe: "o trabalho educativo é o ato de produzir, direta e intencionalmente, em cada indivíduo singular, a humanidade que é produzida histórica e coletivamente pelo conjunto dos homens". Assim, considera-se que o objetivo da educação é intensificar a oferta dos elementos culturais necessários ao indivíduo e sua formação humana integral.

Para Saviani (2013), o acesso aos conhecimentos historicamente produzidos seria garantido pela efetivação dos currículos escolares, cujos conteúdos e estratégias devem romper com o estreito preparo para o mercado do trabalho. Sem "a formação da consciência de classe não existe organização e sem organização não é possível a transformação revolucionária da sociedade" (SAVIANI, 2013, p.7).

\section{CURRÍCULO ESCOLAR E O VIÉS NEOLIBERAL}

A organização do trabalho pedagógico e formativo na escola está expressa no currículo. Esse é composto por conteúdos que, mediados, formam homens de maneira emancipada ou naturalizada, mesmo que prevaleça a lógica neoliberal. No atual momento, vivenciam-se o abalo das bases democráticas, o surgimento de reformas educacionais e trabalhistas, a diminuição de investimentos na educação, os contingenciamentos e cortes nas pesquisas nacionais, as propostas de privatização das universidades públicas e a demasiada influência dos organismos internacionais na adoção de bases antidemocráticas e na redefinição no papel do Estado por meio de seu empresariamento (CASIMIRO, 2018). Assim, urge pensar em uma organização curricular que promova uma educação justa e democrática para a formação de homens emancipados.

Em 20 de dezembro de 2017, com a aprovação da Base Nacional Comum Curricular - BNCC (BRASIL, 2017) pelo Conselho Nacional de Educação - CNE e homologação pelo Ministério da Educação - MEC, ficou legalmente formalizado que as escolas públicas e privadas de todo país iriam aderir a esta política curricular. A BNCC (BRASIL, 2017), documento resultante de um processo de reforma curricular da educação básica, levou à necessidade de se pensar no currículo escolar como instrumento ativo e político que desempenhe um importante papel na formação de pessoas emancipadas, capazes de expressar ideias e opiniões diferentemente dos ideais propostos pela BNCC. Em nossa perspectiva de emancipação, comungamos com Adorno $(1995$, p.120) quando afirma que "é necessário contrapor-se a uma ausência de consciência". Entendemos, como o autor, que a educação deve ser capaz de promover a apreensão e a compreensão da totalidade dos fenômenos, fatos e acontecimentos históricos e, ainda, desenvolver a capacidade de intervir consciente, crítica e politicamente na realidade excludente da sociedade capitalista. 
LUCILENE, A.; MACEDO, A. G. de i MOREIRA, J. A. da S.

O pressuposto é de que o currículo escolar é um instrumento indispensável para planejar ações pedagógicas para que o conhecimento seja assimilado e apreendido pelos estudantes. No entanto, os currículos escolares sempre foram moldados para não romper com a ordem estabelecida e para formar o sujeito que a sociedade necessita para o mercado. Vale lembrar que "o currículo escolar se compõe com a busca de uma igualdade entre os concidadãos iguais na lei, perante a lei, na declaração de direitos" (CURY; REIS; ZANARDI, 2018, p. 19), portanto, os conteúdos previstos no currículo, quando criticamente mediados são fundamentais para a formação de consciência dos sujeitos.

Como as escolas têm a função de propiciar os conhecimentos a todos os estudantes, o currículo escolar torna-se essencial para que o direito à aquisição dos conhecimentos científicos possa se efetivar. Libâneo (2016) salienta o papel das políticas educacionais na efetivação desse direito, mas alerta:

As políticas oficiais para a escola em nosso país se apresentam hoje em duas orientações curriculares complementares, subordinadas à lógica das políticas de contenção da pobreza, atendendo às estratégias de manter a competitividade no contexto da globalização e da diversificação dos mercados (LIBÂNEO, 2016, p. 49).

Assim, o compromisso maior da educação deve ser o de assegurar um currículo que promova uma leitura crítica do mundo de forma integral e favoreça, de fato, o desenvolvimento humano, integrando a constante luta pelo reconhecimento e pela valorização das instituições escolares públicas como um local de apropriação do conhecimento historicamente produzido que desenvolva intelectualmente os estudantes.

Acompanhando a história da formulação dos currículos no Brasil, verificamos que sua origem remonta aos anos de 1930, ao contexto de intensas mudanças sociais correspondentes ao processo de urbanização e industrialização fundamentado em conceitos liberais. Sacristán (2000, p. 40) afirma que os currículos sempre foram alvo de influências externas ao contexto educacional brasileiro e compreendidos como "lista de conteúdos. Ao se expressar nesses termos, é mais fácil de regular, controlar, assegurar sua inspeção, etc., do que qualquer outra fórmula que contenha considerações de tipo psicopedagógico".

A influência de organismos do Sistema da Organização das Nações Unidas (ONU) na configuração da política curricular, nomeadamente após a década de 1990 , foi crescente. Silva e Moreira (2019), ao analisar as propostas curriculares e a influência do Banco Mundial no contexto do pós-golpe (2016-2018), consideram que educação é o meio para fomentar o mercado. Assim, a educação, na perspectiva neoliberal, é a ferramenta para formar indivíduos flexíveis e adaptados que atendam às demandas do capital, já que, "cada vez mais precarizados, os trabalhadores, diante da nova era de precarização estrutural do trabalho, tendem a ser formados na escola para se adaptar às mudanças estruturais do mundo do trabalho" (SILVA; MOREIRA, 2019, p. 155). 
Um dos pontos da reforma educacional promovida desde a década de 1990 foi a elaboração de um currículo escolar baseado nas categorias políticas de competências e habilidades e nos fundamentos contidos no relatório Educação: um tesouro a descobrir - Relatório para a Unesco da Comissão Internacional sobre Educação para o século XXI (DELORS, 1998). Nesse relatório, em associação com organismos internacionais, como o BM, defendem-se os princípios econômicos do neoliberalismo, atrelando-se a educação ao sistema excludente da ordem capitalista. Nesse momento, nos países considerados periféricos e vulneráveis, a educação se molda às propostas e aos ditames desses organismos (MOREIRA; LARA, 2012). Ao longo do documento mencionado, estão elencados os princípios de formação que devem nortear a escola pública, dentre os quais se destacam quatro pilares: aprender a conhecer, aprender a fazer, aprender a viver junto e aprender a ser (DELORS, 1998, p.90).

Em nossa pesquisa, percebemos que as políticas curriculares ainda têm adotado os pilares do Relatório Delors (1998) e, centrando-se na formação para o "saber fazer", contribuem para a permanência da divisão de classes. Notamos que, nessas reformas curriculares, os conhecimentos científicos são desvalorizados para satisfazer às demandas imediatas da sociedade, nas quais se enfatiza a formação por competências e habilidades. Na Resolução CNE/CP n 02/2017 (BRASIL, 2017) está explícito no Art. $3^{\circ}$ que competências correspondem à mobilização dos conceitos e procedimentos e “habilidades (práticas cognitivas e socioemocionais), atitudes e valores, para resolver demandas complexas da vida cotidiana, do pleno exercício da cidadania e do mundo do trabalho".

Essa é a base da política curricular educacional nacional que orienta a construção do currículo escolar. Esse processo, que se reflete nas formas de pensar a apropriação de conhecimentos na escola, é engendrado e definido pelo momento histórico, social, econômico e cultural desta sociedade. É por meio do currículo escolar que se define o que deve ser aprendido e o que é ensinado nas escolas, o que nos leva a pensar quais conhecimentos favorecem a formação de sujeitos emancipados de forma que cada um construa sua própria história em busca de uma sociedade mais justa e igualitária.

Consideramos que a escola pode resistir à lógica da reprodução do capital, desde que sua gestão seja permeada por ações significativas que libertem os homens das amarras dos opressores donos do capital. Segundo Freire (2015), tratar de um currículo escolar problematizador envolve pensar, conhecer, dialogar, debater, questionar e discutir coletivamente no âmbito das políticas públicas educacionais. Assim, é possível pensar em um currículo que não se torne um instrumento a favor dos opressores, da burguesia, mas, sim, que seja ressignificado de conteúdos e garanta a aprendizagem como um direito constitucional de todos.

Diante dos importantes aspectos abordados neste texto, salientamos que, nas últimas décadas, sobretudo a partir das discussões da Base Nacional Comum Curricular (BRASIL, 2017), os profissionais da educação brasileira estão demonstrando preocupação com a política curricular que se instaura no país. Assim, indagamos: a partir do legado de 
LUCILENE, A.; MACEDO, A. G. de i MOREIRA, J. A. da S.

Paulo Freire, como é possível a construção de um currículo que de fato propicie a todos os conhecimentos historicamente elaborados? Em que sentido uma política curricular pode favorecer uma educação emancipatória para os homens e mulheres?

POR UMA POLÍTICA CURRICULAR JUSTA E DEMOCRÁTICA: CONTRIBUIÇÕES DE PAULO FREIRE

Como proposta na Base Nacional Comum Curricular (BRASIL, 2017), o currículo escolar está se constituindo como um reprodutor de princípios do neoliberalismo. Por meio de mecanismos de exclusão e de meritocracia, o currículo tem sido incapaz de levar homens e mulheres a se apropriarem dos conhecimentos para uma transformação social. Michel Apple (2017, p. 15) analisou a educação e suas determinações em diversas obras, mas, especialmente em $A$ educação pode mudar a sociedade, ele enfatizou que a educação "passou a ser vista como fábrica de resultados de testes e com trabalhadores dóceis" (APPLE, 2017, p. 15), porém, com suas finalidades específicas, pode ser resistente às práticas excludentes. Apple (2017, p. 16), compreendendo que a educação pode mudar uma sociedade, afirma: "uma educação que não é meramente ideal corporativo e que não é transformada em negócio pode fazer a diferença na vida das pessoas".

Diante da atual realidade educacional, destacamos o trabalho e o legado de Paulo Freire (1921-1997), um importante educador e pesquisador que apreendeu a essência e o poder que a educação tem para a formação humana. Segundo Fischman (2011), Paulo Freire, atuando em defesa de uma educação para os oprimidos, foi de importância imensurável para a história da educação brasileira: "com palavras e ações, conferem significativamente e sugerem direções a uma sociedade. Estou certo de que Freire foi um educador e pensador talentoso e, sem dúvida, foi um dos melhores modelos de intelectual engajado" (FISCHMAN, 2011, p. 263).

Paulo Freire (2005) defendia um ensino atrelado à politização de homens e mulheres, pois isso resultaria na formação de opinião crítica e em sua atuação nas mais diversas situações excludentes, desafiadoras, discriminatórias em que se encontravam. Em Pedagogia do Oprimido (2005), o autor explicita sua ideia de que a educação, com o objetivo de conscientizar os alunos para poder transformar a realidade, passa pela leitura do mundo. Dentre as importantes ideias de Paulo Freire, destacamos as que se encontram expostas em Pedagogia do oprimido (2005) e Pedagogia da esperança - um reencontro com a Pedagogia do oprimido (2015). Tais considerações são basilares para se pensar em um currículo escolar que propicie a ação e a reflexão sobre os conteúdos e que objetive uma nova sociedade, mais justa, politizada, solidária e democrática.

Em Pedagogia do oprimido (2005), contribuindo para essa nova perspectiva de sociedade, o autor analisa a relação entre opressores e oprimidos e defende a educação como uma prática libertadora, problematizadora, significativa, dialógica e transformadora, ou seja, como instrumento de emancipação humana. Com esse viés, a educação vai além dos muros escolares em que professores e estudantes constroem conhecimentos significativos de forma partilhada.

Neste sentido, a educação libertadora, problematizadora, já não pode ser o ato de depositar, ou de narrar, ou de transferir, ou de 
Au (2011) esclarece que, do legado freiriano, duas abordagens são importantes: a problematização e o diálogo. Por problematização, ele entende as reflexões e perguntas críticas que os educandos fazem a respeito do mundo em que vivem. Disso surgiram os temas geradores para o desenvolvimento de análises e reflexões. Ao se referir ao diálogo, Freire (2005) o caracteriza como um promotor do desenvolvimento de consciência crítica e, em consequência, da transformação social. É por meio do diálogo entre professores e educandos que se constroem conhecimentos, embora o professor seja o responsável por sistematizar o ensino:

conforme aponta Freire, os educadores libertários têm de ser "radicalmente democráticos" em sua pedagogia que se traduz em ser "responsável e diretivo" na sala de aula, ao mesmo tempo respeitando os direitos e as capacidades dos estudantes de chegar a suas próprias conclusões (AU, 2011, p. 252).

O currículo, na visão freiriana, torna-se uma categoria política cujo compromisso é a transformação da ordem social desigual. Para que isso ocorra, é necessário o envolvimento de todos os interessados em uma educação libertária na qual o conhecimento resulte de experiências coletivas. Nesse sentido, o professor "é o orientador e promove reflexões sobre a capacidade de cada um para reconhecer a desigualdade estabelecida, buscando uma verdadeira transformação educacional. Freire (2005, p. 183) salienta: "seria realmente ingenuidade esperar das elites opressoras uma educação de caráter libertário".

Haddad (2019) salienta que Paulo Freire liderou o Programa de Alfabetização Nacional, cujo objetivo era aumentar o número de pessoas alfabetizadas e politizar os menos favorecidos a fim de que pudessem expressar sua opinião política e participar do processo de escolha de seus representantes. Com isso, o programa passou a ser visto pelo governo militar como uma ameaça ao poder, já que a politização almejada por Freire poderia acarretar um movimento de resistência popular.

Segundo Paulo Freire (2005), a educação tem uma importante missão social a cumprir, principalmente quando se pensa em um currículo politizador que propicie aos menos favorecidos da classe popular a visão crítica dos fatos. Para tanto, os conteúdos precisam ser construídos coletivamente com os estudantes, com base em suas próprias experiências e sua visão de mundo: 
LUCILENE, A.; MACEDO, A. G. de; MOREIRA, J. A. da S.

Não reduzimos, por isso mesmo, sua compreensão, a do currículo explícito, a uma pura relação de conteúdos programáticos. Na verdade, a compreensão do currículo abarca a vida mesma da escola, o que nela se faz ou não se faz, as relações entre todos e todas as que fazem a escola. Abarca a força da ideologia e sua representação não só enquanto ideias mas como prática concreta. No currículo oculto o "discurso do corpo", as feições do rosto, os gestos, são mais fortes do que a oralidade. A prática autoritária concreta põe por terra o discurso democrático dito e redito (FREIRE, 2000, p. 123).

Para que, dialogicamente, a conscientização e a politização possam superar as formas de opressão e de desigualdade, a construção do currículo deve prever que os conhecimentos aprendidos sejam problematizados e contextualizados tendo em vista a vivência de cada um: "enquanto objetos de conhecimento, os conteúdos se devem entregar à curiosidade cognoscitiva de professores e alunos. Uns ensinam e, ao fazê-lo, aprendem. Outros aprendem e, ao fazê-lo, ensinam" (FREIRE, 2015, p. 154). Nessa perspectiva, o professor, em uma relação dialógica, aprende com os alunos e os alunos aprendem com seus professores, tornando a relação docente e discente dialógica, de forma que as vivências dos estudantes sejam valorizadas no contexto da sala de aula, transformando-se em novos conteúdos: "não há prática educativa sem conteúdo" (FREIRE, 2015, p. 155). Conforme o autor (2015), esses conteúdos necessitam ser problematizados e investigados junto aos alunos para que se transformem em novos conhecimentos críticos e significativos.

Estabelecer uma nova realidade no trabalho com os conteúdos nas escolas é uma tarefa que exige diversas transformações no campo social, cultural, político, ideológico e, principalmente, econômico, uma vez que a educação sempre foi determinada pelo modo de produção e de organização do trabalho, formando o ideal de homem necessário para manter a relação entre opressores e oprimidos. $\mathrm{Na}$ concepção de Freire (2005), uma nova sociedade somente será instituída por meio da educação, o que implica a necessidade de se aliar prática, teoria e reflexão para, assim, desenvolver o pensamento crítico dos estudantes e aguçar sua vontade de transformar o mundo em algo diferente do atual.

E esta luta somente tem sentido quando os oprimidos, ao buscarem recuperar sua humanidade, que é uma forma de recriá-la, não se sentem idealistamente opressores, mas restauradores da humanidade em ambos. E aí está a grande tarefa humanista e histórica dos oprimidos - libertar-se a si e aos opressores (FREIRE, 2005 p. 41).

Nessa direção, compreendemos que uma política curricular planejada sem a participação de todos os profissionais da educação nunca é neutra. Ao ser colocada em prática, para que não contribua para a reprodução da lógica do mercado, é necessário que haja o debate, a reflexão e a ação dos educadores. Freire $(2015$, p. 152) nos ensina que "O problema fundamental, de natureza política e tocado por tintas ideológicas, é 
saber quem escolhe os conteúdos, a favor de quem e de que estará o seu ensino, contra quem, a favor de que, contra quê". Eis aqui uma importante contribuição de Freire em Pedagogia da Esperança - um reencontro com a Pedagogia do Oprimido (2015) para se pensar coletivamente em políticas curriculares que fortaleçam os menos favorecidos.

Na contracorrente dessa concepção, sobretudo a partir dos anos de 2015, 2016 e 2017, com a reforma curricular denominada Base Nacional Comum Curricular - BNCC (BRASIL, 2017), foi definido na educação brasileira o objetivo de padronizar os currículos das escolas públicas e privadas. A homologação da BNCC (BRASIL, 2017) deu-se com pouca participação de pesquisadores em educação e de professores da educação básica e, com isso, tal política traçou um caminho inverso ao proposto pelo educador Paulo Freire, qual seja, o do diálogo, da problematização, da politização e da concretização coletiva de um currículo.

Observamos que as ideias e proposições defendidas por Paulo Freire causam grande incômodo, pois se contrapõem aos conceitos defendidos na atual conjuntura governamental. Para garantir os ditames da sociedade neoliberal, nega-se aos oprimidos o direito ao conhecimento politizado, de forma a torná-los mais facilmente manipuláveis. Nita Freire (2019), viúva do educador, afirma que o legado de Paulo Freire incentiva todo professor a buscar uma nova educação que rompa com os preceitos neoliberais implícitos e explícitos nos conteúdos escolares.

\begin{abstract}
A politicidade, como outro fundamento da teoria e da práxis de Paulo Freire, explicita a natureza política da educação, negando a neutralidade no ato educativo. Tem sua relação com a conscientização. Isto é, leva os indivíduos a se conscientizarem do fato de que o educador (a) de toda natureza quer mudar e agir com esse objetivo como um projeto de vida. Portanto, quer comprometer-se com a superação das injustiças sociais de toda sorte que nascem, sobretudo com as diferenciações dos níveis de educação de modo geral e não só pela qualidade de ensino escolar posta à disposição (ou até não posta) para a população nacional. Solidarizar-se com os oprimidos e excluídos no processo educacional, mas sobretudo, nas possibilidades de inserção deles nos destinos de seu país (FREIRE, 2019, p. 6-7).
\end{abstract}

Dessa forma, as discussões educacionais precisam contemplar fundamentalmente a relação dialógica, crítica e reflexiva a respeito da sociedade, para, assim, levar à constituição de novos homens e mulheres politicamente esclarecidos e capazes de transformar uma realidade opressora. Reis (2012) aponta as contribuições inquestionáveis de Freire para a educação brasileira, especialmente sua preocupação em ofertar a educação aos excluídos.

O discurso de Paulo Freire, por ter um forte engajamento político e social, buscou despertar no povo uma ação transformadora a partir do conhecimento formal, através da escrita e da leitura. A grande 
LUCILENE, A.; MACEDO, A. G. de i MOREIRA, J. A. da S.

contribuição do educador foi tratar o ensino como um fato de linguagem, como circunstância política, aliando conhecimento à consciência cidadã (REIS, 2012, p. 20).

Assim, conforme as considerações freirianas presentes em Pedagogia do Oprimido (2005) e Pedagogia da Esperança - um reencontro com a Pedagogia do Oprimido (2015), a escola não deve ser transmissora dos conteúdos e conceitos postos pelos opressores e sim ser condutora e mediadora no processo de análise da realidade e de conscientização dos estudantes a respeito da libertação da opressão.

\section{CONSIDERAÇÕES FINAIS}

Conforme as análises apresentadas, deixamos evidente que, historicamente, os conteúdos trabalhados na instituição escolar e presentes no currículo são, de modo geral, determinados pelo modo de produção e pela organização no mundo do trabalho pela classe dominante. Ao discutirmos a intensificação do neoliberalismo, seu viés mais autoritário, e a destruição dos direitos sociais, tivemos como finalidade apresentar questões que nos levam a defender uma nova vertente de currículo alicerçado na resistência ativa das proposições de Paulo Freire e seu legado. Ou seja, nossa intenção foi defender a adoção de um currículo dialógico que problematize situações reais, capaz de, por meio dos conhecimentos sistematizados, fundantes para o alcance da transformação social, promover a criticidade e a emancipação humana.

A discussão sobre as políticas curriculares no Brasil não pode ignorar o quanto a essência dos princípios neoliberais está arraigada na escola pública. São as demandas do capitalismo em face das transformações econômicas, culturais e sociais que continuam a nortear os conteúdos dos currículos escolares, o que implica formar sujeitos que tenham cada vez mais dificuldade para romper com a lógica excludente desse sistema desigual.

As conjecturas de Paulo Freire $(2005 ; 2015)$ desafiam-nos a implementar uma nova proposta curricular, a pensar na possibilidade de promover uma educação politizada e questionadora que parta da realidade vivenciada pelos estudantes. Porém, isso exige a luta contra o sistema neoliberal que explora os sujeitos e os impede de transformar essa realidade socialmente injusta e opressora.

Quem, melhor que os oprimidos, se encontrará preparado para entender o significado terrível de uma sociedade opressora? Quem sentirá, melhor que eles, os efeitos da opressão? Quem, mais que eles, para ir compreendendo a necessidade da libertação? Libertação a que não chegarão pelo acaso, mas pela práxis de sua busca; pelo conhecimento e reconhecimento da necessidade de lutar por ela (FREIRE, 2015, p.43).

A educação somente cumprirá sua função social se fizer prevalecer uma relação dialética no âmbito escolar, se proporcionar, por meio dos conhecimentos historicamente elaborados, a formação de sujeitos críticos, pensantes e atuantes para a democratização e a transformação da sociedade brasileira. Cabe-nos, enquanto 
educadores, a defesa e a prática de uma educação que emancipe, enfrentando um duplo desafio: lutar para termos uma educação com currículos sólidos e, por meio da resistência e da apropriação dos conhecimentos científicos compreendidos historicamente, mudar o sistema. Como nos ensinou Paulo Freire, a escola somente se tornará democrática e politizada quando formar sujeitos críticos e emancipados, que, aprofundando coletivamente os conteúdos clássicos, humanísticos, científicos e filosóficos, adquiram uma consciência crítica que ultrapasse o senso comum.

Artigo recebido em: 30/03/2021

Aprovado para publicação em: 29/06/2021

\section{CURRICULAR POLICIES AND NEOLIBERALISM: A CRITICISM OF THE NATIONAL COMMON CURRICULAR BASE (BNCC) BASED ON THE FREIRIAN LEGACY}

ABSTRACT: In this article, we analyze the political-economic ideology of neoliberalism present in the curriculum policy of primary education in the context of the approval of the BNCC and establish an opposite relation with the Freirian legacy, especially with its concept of a questioning, fair and democratic school. Methodological proposals are based on the analysis and understanding of the historical, political and economic situation at the time. The text is composed by the results of an exploratory research, of bibliographic aspect, about the main ideas of neoliberalism, economic doctrine that ends up justifying the principles of inequality and social exclusion. The results are analyzed looking ideally at the proposal of a questioning curriculum that contains appropriate knowledge to a conception of a school that lacks the logic of the market. At last, it is considered that Paulo Freire proposes a curriculum built from the students' reality and capable of reducing, through knowledge, the inequalities that were generated by the adoption of neoliberalism.

KEYWORDS: Curricular Policy. Paulo Freire. Neoliberalism. Emancipation. BNCC.

POLÍTICA CURRICULAR Y NEOLIBERALISM: UNA CRÍTICA DE LA BASE COMÚN DEL PLAN DE ESTUDIOS NACIONAL A PARTIR DEL LEGADO FEIRIANO

RESUMEN: En el artículo se analiza el ideario político económico de neoliberalismo presente en la política curricular de la educación básica y en el contexto de la aprobación de BNCC y se establece una relación de contraposición con el legado de Paulo Freire, especialmente con su concepción de escuela problematizadora, justa y democrática. Se presentan propuestas metodológicas basadas en el análisis y comprensión de la situación histórica, política y económica actual. El texto es compuesto por los resultados de una búsqueda exploratoria, de carácter bibliográfica, a respecto de los principales postulados del neoliberalismo, dotrina económica qué acaba por justificar los 
LUCILENE, A.; MACEDO, A. G. de; MOREIRA, J. A. da S.

principios de la desigualdad y de la exclusión social. Los resultados son analizados a luz de la propuesta de un currículo problematizador, compuesto por conocimientos apropiados a una concepción de escuela despojada de la lógica del mercado. Se considera, por tanto, que Paulo Freire propone un currículo construido a partir de la realidad de los estudiantes y capaz que disminuyera, por el conocimiento, la desigualdad resultante de la adopción del neoliberalismo.

PALABRAS CLAVE: Política Curricular. Paulo Freire. Neoliberalismo. Emancipación. BNCC.

Nota

Theodore Willian Schultz (1902-1998), na década de 1960, foi o pioneiro nas formulações dos postulados econômicos da Teoria do Capital Humano. Atualmente, a teoria é difundida por Gary Becker e Frederick Harbison. A Teoria do Capital Humano, o investimento em capacitar e ampliar as habilidades e competências do homem, pode contribuir para o desenvolvimento econômico do pais e gerar uma competição benéfica para o setor produtivo.

\section{REFERÊNCIAS}

ADORNO, T. W. Educação e emancipação. In: Educação e emancipação. Rio de Janeiro: Paz e Terra, 1995.

ALVES, G; MOREIRA, J.; PUZIOL, J. Educação profissional e ideologia das competências: elementos para uma crítica da nova pedagogia empresarial sob a mundialização do capital. Revista de Educação Educere et Educare, Cascavel, v. 4, n. 8 jul./dez., p. 45-59, 2009.

APPLE, W. M. A educação pode mudar a sociedade? Petrópolis: RJ, Vozes, 2017.

AU, W. Lutando com o texto: contextualizar e recontextualizar a pedagogia de Freire. IN: APPLE, W. M; AU, W.; GANDIN, L. A. Educação crítica: análise internacional. Tradução de Vinícius Ferreira. Revisão Técnica de Luís Armando Gandin. Porto Alegre: Artmed, 2011.

BALL, S. J. Educação Global S.A.: novas redes políticas e o imaginário neoliberal. Ponta Grossa: UEPG, 2014.

BRASIL. CONSELHO NACIONAL DE EDUCAÇÃO. CONSELHO PLENO. Resolução CNE/CP n० 2, de 22 de dezembro de 2017. Disponível em: $<$ http://portal.mec.gov.br/index.php?option=com_docman\&view=download\&alias=796 
Política curricular e neoliberalismo: uma crítica à base nacional...

Dossiê 120

1 -rcp002-17-pdf\&category_slug=dezembro-2017-pdf\&ltemid=30192>. Acesso em: ago. 2019.

BRASIL. Ministério da Educação. Base nacional comum curricular - BNCC $3^{\text {a }}$ versão. Brasília, DF, 2017.

CASIMIRO, F. H. C. A nova direita: aparelhos de ação política e ideológica no Brasil contemporâneo. São Paulo: Expressão Popular, 2018.

CORRÊA, A.; MORGADO, J. C. A construção da Base Nacional Comum Curricular no Brasil: tensões e desafios. In: Colóquio Luso-Brasileiro de educação - COLBEDUCA, 3, 2018, Braga. Anais [...]. Braga: Uminho, 2018.

CURY, C. R. J. Educação e contradição: elementos metodológicos para uma teoria crítica do fenômeno educativo. São Paulo: Cortez: Autores Associados, 1987.

CURY, C. R. J. REIS, M. ZANARDI, T. A. C. Base Nacional Comum Curricular: dilemas e perspectivas. São Paulo: Cortez, 2018.

DELORS, J. Educação: um tesouro a descobrir. Relatório para a UNESCO da Comissão Internacional sobre Educação para o século XXI. São Paulo: Cortez, 1998.

FISCHMAN, G. E. A (não) domesticação da Pedagogia do oprimido. In: APPLE, W. M; AU, W.; GANDIN, L. A. Educação crítica: análise internacional. Tradução de Vinícius Ferreira. Revisão Técnica de Luís Armando Gandin. Porto Alegre: Artmed, 2011.

FREIRE, N. Palavra aberta - O legado da obra de Paulo Freire para a educação global contra-hegemônica. Educação em Revista, Belo Horizonte, v.35, 2019.

FREIRE, P. Educação como prática da liberdade. 24. ed. Rio de janeiro, Paz e Terra. 2000.

FREIRE, P. Pedagogia da esperança: um reencontro com a pedagogia do oprimido. 15. ed. Rio de Janeiro: Paz \& Terra. 2015.

FREIRE, P. Pedagogia do Oprimido. 43. ed. Rio de Janeiro, Paz e Terra, 2005.

HADDAD, S. Paulo Freire, o educador proibido de educar. In: CASSIO, F (org.). Educação contra a barbárie: por escolas democráticas e pela liberdade de ensinar. 1. ed. São Paulo: Boitempo, 2019, p. 141-417. 
LUCILENE, A.; MACEDO, A. G. de; MOREIRA, J. A. da S.

LAVAL, C. A escola não é uma empresa: o neoliberalismo em ataque ao ensino público. São Paulo: Boitempo, 2019.

LIBÂNEO, J. C. Políticas educacionais no Brasil: desfiguramento da escola e do conhecimento escolar. Cadernos de Pesquisa, São Paulo, v. 46, n. 159. 2016.

MOREIRA, J. A. S; LARA, A. M. B. Políticas Públicas para a educação infantil no Brasil (1990-2001). Maringá: EDUEM, 2012.

ORGANIZAÇÃO DAS NAÇÕES UNIDAS PARA A EDUCAÇÃO, A CIÊNCIA E A CULTURA UNESCO. Educação 2030: Declaração de Incheon e Marco de Ação; rumo a uma educação de qualidade inclusiva e equitativa e à educação ao longo da vida para todos. Brasília, DF, 2016.

PUELLO-SOCARRÁS, J.F. Nueva Gramática del Neo-liberalismo: Itinerarios teóricos, trayectorias intelectuales, claves ideológicas. Bogotá: Universidad Nacional de Colombia, Facultad de Derecho, Ciencias Políticas y Sociales, 2008

PUELLO-SOCARRÁS, J. F. Novo neoliberalismo: arquitetônica estatal no capitalismo do século XXI. Revista Eletrônica de Administração - REAd, Porto Alegre, v. 27,n. 1, janeiro/abril 2021, p. 35-65.

REIS, P. J. F. M. Paulo Freire - análise de uma história de sua vida. 2012. $199 \mathrm{f}$. Dissertação (Mestrado em Letras) - Programa de Mestrado em Letras, Universidade Federal de São João Del Rei, São João Del Rei. 2012.

SACRISTÁN, J. G. O currículo: uma reflexão sobre a prática. 3.ed. Porto Alegre: Artmed, 2000.

SAVIANI, D. Pedagogia histórico-crítica: primeiras aproximações. 11. ed. Campinas: Autores Associados, 2013.

SILVA, R. V.; MOREIRA, J. A. S. A educação, reformas curriculares e as propostas do Banco Mundial no contexto pós-golpe (2016-2018). Colloquium Humanarum, Presidente Prudente, v. 16, n. 1, jan/mar 2019, p.145-162.

SOUZA, Â. R. Reformas educacionais: descentralização, gestão e autonomia escolar. Educar, Curitiba, n. 22, 2003, p. 17-49.

VIANA, N. Breve história do neoliberalismo. Revista Enfrentamento, São Paulo, n. 05, p. 4-10, jul/dez., 2008. 
LuCilene Amarante: Mestre em Educação pela Universidade Estadual de Maringá/Paraná. Doutoranda do Programa de Pós-Graduação em Educação (PPE/UEM) na linha de Políticas e Gestão em Educação. Docente da Educação Básica do Sistema Municipal de Educação de Sarandi/Paraná. Integrante do Grupo de Estudos e Pesquisas em Políticas Educacionais, Gestão e Financiamento da Educação - GEPEFI/CNPq.

Orcid: https://orcid.org/0000-0002-7994-4164

E-mail: lucileneamarante@hotmail.com

Andressa Garcia de MACEDo: Mestranda em Educação na Universidade Estadual de Maringá (UEM-PR). Licenciada em Pedagogia (UEM). Docente da Educação Básica na rede municipal de ensino de Maringá/Paraná. Integrante do Grupo de Estudos e Pesquisas em Políticas Educacionais, Gestão e Financiamento da Educação - GEPEFI/CNPq.

Orcid: https://orcid.org/0000-0002-0870-7065

E-mail: dessa.kenes@gmail.com

Jani Alves da Silva Moreira: Doutora em Educação pela Universidade Estadual de Maringá - UEM. Docente Associado do Departamento de Teoria e Prática da Educação e do Programa de Pós-Graduação em Educação da Universidade Estadual de Maringá UEM, Maringá, PR. Realizou pós-doutorado na Universidade Federal do Paraná (UFPR), com estágio pós-doutoral no Programa de Pós-Graduação em Educação da Faculdade de Educação da Universidade de Salamanca (USAL), na Espanha. Líder do GEPEFI/CNPq - Grupo de Estudos e Pesquisa em Políticas Educacionais, Gestão e Financiamento da Educação.

Orcid: https://orcid.org/0000-0002-3008-0887

E-mail: jasmoreira@uem.br

Este periódico utiliza a licença Creative Commons Attribution 3.0, para periódicos de acesso aberto (Open Archives Initiative - OAI). 